\title{
Letter to the Editors
}

\section{Acute oxcarbazepine overdose in an autistic boy}

\section{Maura Pedrini, Antoni Noguera, Joan Vinent, ${ }^{1}$ Mercè Torra ${ }^{2} \&$ Rafael Jiménez}

Paediatrics and 'Pharmacy Departments, Hospital Sant Joan de Déu, Esplugues and ${ }^{2}$ Pharmacology and Toxicology

Department, Hospital Clínic, Universitat de Barcelona, Barcelona, Spain

Oxcarbazepine (OXC), a 10-keto analogue of carbamazepine, is an antiepileptic drug licensed for the treatment of partial seizures in children and adults, as monotherapy or adjunctive therapy [1]. In humans, OXC is rapidly metabolized in liver to 10-monohydroxy-carbazepine (MHD), its active metabolite. MHD blocks voltage-sensitive sodium channels, stabilizing hyperexcited neuronal membranes, thereby inhibiting repetitive firing and decreasing the propagation of synaptic impulses [2]. Recently, successful use of OXC in the management of disruptive behaviours in autistic patients has also been reported [3].

Despite the fact that experience with OXC in the paediatric age is still limited, several observational studies indicate that the drug has a good long-term tolerability profile $[4,5]$. In clinical practice, the most commonly observed adverse events are rash, fatigue, nausea and somnolence [4]. Only four cases of OXC acute overdose have been reported to date [6-9], none of them in a paediatric patient. We describe the case of a 13-year-old boy who presented with somnolence after the ingestion of $15 \mathrm{~g}$ of $\mathrm{OXC}$, and provide concomitant serum concentrations of both OXC and MHD.

A 13-year-old boy (weight $60 \mathrm{~kg}$, height $175 \mathrm{~cm}$ ) was brought to the Emergency Department by his mother because of accidental ingestion of $250 \mathrm{ml}$ of Trileptal ${ }^{\mathrm{TM}}$ suspension (OXC solution, $60 \mathrm{mg} \mathrm{l}^{-1}$; Novartis, Barcelona, Spain) $1 \mathrm{~h}$ before; he had vomited shortly after the intake. No other drugs had been ingested. The patient had been diagnosed with autism spectrum disorder at the age of 4 years and was receiving risperidone (1 $\mathrm{mg}$ three times a day; Risperdal Flas ${ }^{\mathrm{TM}}$, Janssen-Cilag, Madrid, Spain) from the age of 10 years, together with behaviour modification. Treatment with OXC (300 mg twice daily) had been implemented 6 months earlier to treat persistent aggression towards others and head banging, with good tolerance to treatment and improvement in his disruptive behaviour.

On admission, the patient's vital signs were as follows: blood pressure 105/47; pulse 75 beats $\mathrm{min}^{-1}$; respiratory rate 15 breaths $\mathrm{min}^{-1}$; haemoglobin saturation while breathing room air, $99 \%$; temperature $36.9^{\circ} \mathrm{C}$. He was somnolent (minimal Glasgow Coma Scale 13) but arousable to

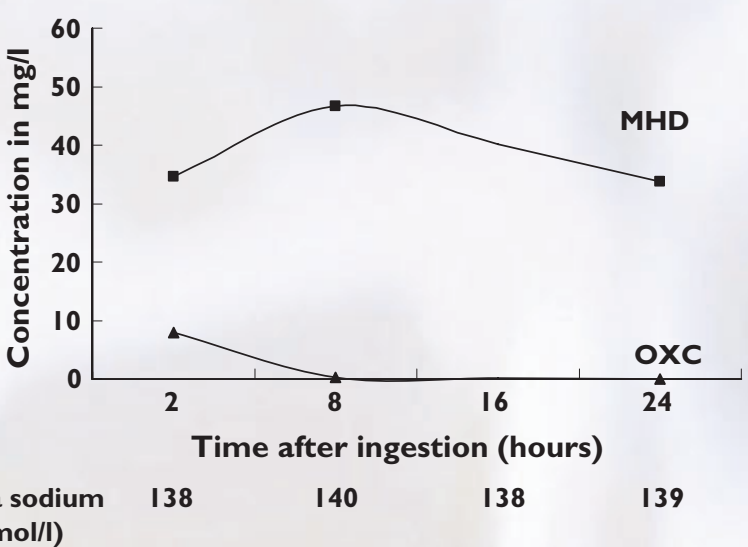

\section{Figure 1}

Evolution in serum concentrations of oxcarbazepine (OXC) and its active metabolite, 10-monohydroxy-carbazepine (MHD), together with plasma sodium levels

pain stimuli. Normal tendon and pupillary reflexes were present. Nystagmus and tremor were not observed; gait disturbances were not evaluable. The rest of the physical examination was unremarkable. The ECG was within normal limits (sinus rhythm, QRS $85 \mathrm{~ms}$, and QTc $410 \mathrm{~ms}$ ), and laboratory testing showed normal values for complete blood count, blood gases, protein and albumin levels, kidney and liver functions, and electrolyte concentrations.

Because of the potential toxicity of the ingested dose of OXC, $60 \mathrm{~g}$ of activated charcoal was administered through a nasogastric tube twice, with an interval of $4 \mathrm{~h}$, and the patient was transferred to the Paediatric Intensive Care Unit, where he remained haemodynamically stable and did not require ventilatory support. The patient's somnolence progressively improved within the following $12 \mathrm{~h}$, although occasional self-limited violent outbursts occurred. Neither other symptoms nor ECG changes or arrhythmias were observed. Sodium plasma levels (performed every 6 h; Figure 1) remained within normal limits, as well as the rest of laboratory results. 
The concentrations of OXC and MHD were determined by a specific high-performance liquid chromatography method with diode array ultraviolet detection. The serum concentration of OXC was $7.9 \mathrm{mg} \mathrm{l}^{-1} 2 \mathrm{~h}$ after the ingestion with a corresponding MHD concentration of $34.6 \mathrm{mg} \mathrm{l}^{-1}$ (Figure 1). OXC was quickly metabolized, its concentration being $0.3 \mathrm{mg} \mathrm{l}^{-1}$ and undetectable 8 and $24 \mathrm{~h}$ after the ingestion, respectively. MHD reached a concentration of $46.6 \mathrm{mg} \mathrm{l}^{-1} 8 \mathrm{~h}$ after the ingestion, and steadily decreased afterwards.

Two days after admission the patient was fully recovered, OXC and risperidone treatment were resumed without incidents and the boy could be discharged.

OXC tablets and suspension have similar bioavailability and are interchangeable on a $\mathrm{mg}$ per $\mathrm{mg}$ basis. The patient we describe ingested 25 times his daily dosage. OXC was rapidly absorbed and reached a concentration of $7.9 \mathrm{mg} \mathrm{I}^{-1}$ $2 \mathrm{~h}$ after the ingestion; maximum serum levels of OXC were twofold higher than those found during steady state in epileptic patients, which are usually $<3 \mathrm{mg} \mathrm{l}^{-1}$. The concentration of MHD after $8 \mathrm{~h}$ was higher than the maximum recommended levels in the treatment of epilepsy (10$\left.35 \mathrm{mg} \mathrm{l}^{-1}\right)$. Regarding clearance parameters, values in children aged $\geq 13$ years approach those of the adult patient. Our results are consistent with previously published pharmacokinetic studies of OXC $[10,11]$.

Very few cases of OXC overdose have been reported to date [6-9]. In all of them, central nervous system depression was rapidly induced and all patients fully recovered with symptomatic and supportive treatment. Although it is unusual to administer multiple doses of activated charcoal to treat poisoning and overdoses, two doses were given in this case based on its use after carbamazepine overdose [12]. Of note, haemodialysis was not useful in accelerating MHD elimination in an adult patient who had ingested $42 \mathrm{~g}$ of OXC, despite this metabolite exhibiting low protein binding, around 40\% [7]; nor was plasmapheresis in another patient with MHD steady-state levels [13]. Most of the patients ingested OXC with other drugs known to be central nervous system depressors, such as alcohol [7] or quetiapine [6]. The patient we present had normally received his risperidone dose at the time of OXC overdose; no drug interactions of OXC with risperidone have been described to date [14]. It is possible that risperidone and the ethanol constituent of the Trileptal ${ }^{\mathrm{TM}}$ formulation increased OXC toxicity in this patient.

Furlanut [7] and Van Opstal [9] reported MHD serum peak levels of 59 and $65 \mathrm{mg} \mathrm{l}^{-1}$, despite massive OXC overdoses of 31 and $42 \mathrm{~g}$, respectively; this was also the case in our patient (overdose around $15 \mathrm{~g}$; MHD maximum serum level $46.6 \mathrm{mg} \mathrm{l}^{-1}$ ). The formation of MHD from OXC is a ratelimiting process and this probably contributes to the relatively low MHD levels after acute OXC intoxication [11]. Whether the clinical findings and benign evolution of OXC overdose would have been different with higher MHD serum levels remains unknown.
Subclinical hyponatraemia in OXC-treated paediatric patients usually develops during the first 3 months of treatment in up to $25 \%$. It is probably mediated through an increased level of arginine vasopression in inherently susceptible individuals, being independent of patient's age or gender, eventual antiepileptic comedication, OXC dosage or MHD serum levels [15]. Severe clinically relevant hyponatraemia in children has been seldom reported and, currently, routine monitoring of electrolytes during OXC maintenance therapy is not recommended unless symptoms arise, in the case of renal disease, or if other medications known to reduce sodium levels are used concomitantly. Hyponatraemia has never been described in the setting of an acute OXC overdose.

In summary, the rapid central nervous system depression that usually occurs after OXC overdose and the individual response to the drug emphasize the need for close monitoring of these patients, including haemodynamic and respiratory function, neurological status and electrolyte levels.

\section{REFERENCES}

1 Bang L, Goa K. Oxcarbazepine: a review of its use in children with epilepsy. Paediatr Drugs 2003; 5: 557-73.

2 Tecoma ES. Oxcarbazepine. Epilepsia 1999; 40: S37-46.

3 Kapetanovic S. Oxcarbazepine in youths with autistic disorder and significant disruptive behaviors. Am J Psychiatry 2007; 164: 832-3.

4 Bourgeois BF, D'Souza J. Long-term safety and tolerability of oxcarbazepine in children: a review of clinical experience. Epilepsy Behav 2005; 7: 375-82.

5 Rufo-Campos M, Casas Fernandez C, Martinez-Bermejo A. Long-term use of oxcarbazepine oral suspension in childhood epilepsy: open-label study. J Child Neurol 2006; 21:480-5.

6 Barker MJ, Beitez JG, Ternullo S, Juhl GA. Acute oxcarbazepine and atomoxetine overdose with quetiapine. Vet Hum Toxicol 2004; 46: 130-2.

7 Furlanut M, Franceschi L, Poz D, Silvestri L, Pecorati M. Acute oxcarbazepine, benazepril and hydrochlorothiazide overdose with alcohol. Ther Drug Monit 2006; 28: 267-8.

8 Raja M, Azzoni A. Oxcarbazepine, risperidone and atenolol overdose with benign outcome. Int J Neuropsychopharmacol 2003; 6: 309-10.

9 Van Opstal JM, Janknegt R, Cilissen J, L'Ortije WHVM, Nel JE, De Heer F. Severe overdose with the antiepileptic drug oxcarbazepine. Br J Clin Pharmacol 2004; 58: 329-31.

10 Johannessen SI, Battino D, Berry DJ, Bialer M, Krämer G, Tomson T, Patsalos PN. Therapeutic drug monitoring of the newer antiepileptic drugs. Ther Drug Monit 2003; 25: 347-63. 
11 May TW, Korn-Merker E, Rambeck B. Clinical pharmacokinetics of oxcarbazepine. Clin Pharmacokinet 2003; 42: 1023-42.

12 Montoya-Cabrera MA, Sauceda-García JM, Escalante-Galindo P, Flores-Alvarez E, Ruiz-Gómez A. Carbamazepine poisoning in adolescent suicide attempters. Effectiveness of multiple-dose activated charcoal in enhancing carbamazepine elimination. Arch Med Res 1996; 27: 485-9.

13 Christensen J, Balslev T, Villadsen J, Heinsvig EM, Dam M, Poulsen JH. Removal of 10-hydroxycarbazepine by plasmapheresis. Ther Drug Monit 2001; 23: 374-9.

14 Rosaria Muscatello M, Pacetti M, Cacciola M, La Torre D, Zoccali R, D’Arrigo C, Migliardi G, Spina E. Plasma concentrations of risperidone and olanzapine during coadministration with oxcarbazepine. Epilepsia 2005; 46: $771-4$.
15 Holtmann M, Krause M, Opp J, Tokarzewski M, Korn-Merker E, Boenigk HE. Oxcarbazepine-induced hyponatremia and the regulation of serum sodium after replacing carbamazepine with oxcarbazepine in children. Neuropediatrics 2002; 33: 298-300.

\section{RECEIVED}

5 January 2009

\section{ACCEPTED}

19 February 2009

\section{CORRESPONDENCE}

Maura Pedrini, MD, Paediatrics Department, Hospital Sant Joan de Déu, Passeig Sant Joan de Déu, 2, 08950 Esplugues, Spain. E-mail:mpedrini@hsjdbcn.org 